\title{
APPLICATION OF DIRECT AND INDIRECT METHODS FOR PREDICTING GEOTECHNICAL DAM FOUNDATION ISSUES ON WEATHERED METAMORPHIC ROCKS UNDER TROPICAL CONDITIONS
}

\author{
Marcio Fernandes LEÃO * and Eduardo Antonio Gomes MARQUES
}

Civil Engineering Department, Federal University of Viçosa, Avenida Peter Henry Rolfs, Viçosa - MG, 36570-900 Brazil

*Corresponding author's e-mail: marciotriton@hotmail.com

\begin{tabular}{l}
\hline ARTICLE INFO \\
\hline Article history: \\
Received 1 September 2019 \\
Accepted 10 January 2020 \\
Available online 4 February 2020 \\
\hline
\end{tabular}

Keywords:

Karst cavities

Electrical resistivity

Concrete-gravity dam

Weathering rocks

\begin{abstract}
Weathering profiles in tropical regions usually present great heterogeneity and anisotropy of geological materials. High structural complexity and great bedrock irregularity are added when these profiles are composed of metamorphic rocks. Therefore, geological-geotechnical research initiatives in these regions imply indirect methods associated with direct methods. In this context, we studied the San Juan dam foundation in the Dominican Republic, geologically composed of young residual schist soil cover (up to $20 \mathrm{~m}$ ), in which occurs schist layers of low resistance to SPT ( 2 SPT blows $/ 30 \mathrm{~cm}$ ) consistent with a massive and stratified marble rock, which tends to concentrate karst cavities. This geological condition, associated with the vast extent of the dam influence area, motivated the adoption of an indirect method by electrical resistivity intending to identify sites with the possibility of occurrence of cavities filled or not under the reservoir foundation and in the dam axis itself. Subsequently, a more rational initiative of mixed drillings was carried out in sites with such possibility, resulting in discarding these hypotheses and demonstrating that these cavities correspond to graphite schists and non-karst marbles, competent materials as dam foundation.
\end{abstract}

\section{INTRODUCTION}

Geological-geotechnical investigations are essential for any engineering project regardless of their magnitude, allowing identifying the nature of geological materials and their geotechnical properties. The level of detail and number of investigations are variable. For instance, drilling depths of petroleum and mining engineering projects are often deep due to prospecting, but those used on civil engineering design are shallower even for large dams and deep underground works (Jakobsen and Babendererde, 2017).

The number of investigations and methods used also varies according to the objective, local geological complexity, and level of information on knowledge of soils and rocks in the implantation sites, especially outcrops. The difficulty in obtaining information increases when rocks and soils are in subsurface layers, requiring new techniques for efficient access. This difficulty is even high for weathered materials in terms of sample representativeness and geotechnical properties (Leão et al., 2017).

Conditioning factors must always be observed when a dam construction project is designed, including materials that compose shoulders and foundation and their relationship with stability and water-tightness, as well as the availability of construction materials for the building of the dam. Project success is directly related to the foundation conditions and area of its reservoir. A better detailing increases the constructive success exponentially, but, on the other hand, the investment in elaborated field research leads to an increase in construction costs, which often can make it infeasible. On the other hand, the failure to perform enough investigations, mainly on the projects at sites with many uncertainties, must be solved by emergency solutions, resulting in high unplanned costs (Leão, 2011). Uncertainties associated with the geological environment and basic parameters of engineering projects, such as resistance, deformability, and permeability of materials, lead to the adoption of conservative but more expensive projects, such as foundation excavation up to a reliable rocky massif, which may represent high soil volumes in tropical climate countries, increasing not only the constructive cost but also the environmental impact in a given area (Leão, 2015).

Some cases of dams developed on alteration profiles can be found in the scientific literature, such as Obruk (basalt) (Kocbay and Kilic, 2006) and Keban 
(karst marble and schist) (Ertunç, 1999) in Turkey, Tianhuanping (andesite) (Wang and Liu, 2005) in China, Porthimund (charnockites) (Ramana and Gogte, 1982) and Uri and Nathpa Jhakri (schist rocks) (Behrestaghi et al., 1996) in India, Hickory Log Creek (mica-schist) (Rogers et al., 2006) in the United States, Scott (shales) (Goodman and Ahlgren, 2000) and Clyde (schist) (Macfarlane, 2009) in New Zealand, and Mujib (limestone) (Wiesner and Ewert, 2013) in Jordan, with few publications for schist materials as foundations developed in tropical climate, mainly for projects of concrete gravity dams.

This study aimed to demonstrate how the association of indirect and direct methods was effective in the definition of important geological-geotechnical aspects to support the San Juan concrete gravity dam project located in the Samaná Peninsula, Dominican Republic, founded almost predominantly on a young anisotropic residual soil of interspersed schists and marbles developed under tropical climate.

\section{GEOLOGY}

According to Mollat et al. (2004), the Samaná Peninsula (Fig. 1) is predominantly composed of micaceous schists and marbles with poorly defined boundaries, being part of the belt formed at the end of the Mesozoic and early Tertiary, between the arch of the Spanish islands and Puerto Rico and the Bahamas Carbonate Platform.

The dam area is devoid of rocky outcrops, except immediately downstream, on the right bank, where there is a large block of massif schist rock, one of the only in the region. Intercalation of altered schists and marble, sheared and folded, with preferential foliation orientation of $\mathrm{N} 105^{\circ} / 25^{\circ} \mathrm{SW} \sim \mathrm{N} 125^{\circ} / 80^{\circ} \mathrm{SW}$ are observed at sites near the area. Grades and slopes that limit the reservoir are covered by mantles of residual soils with a thickness of about 10 to $20 \mathrm{~m}$ developed from micaceous schists, measured based on mixed drillings, with a colluvial cover of up to $1.5 \mathrm{~m}$. Rocky outcrops of quartz-feldspathic schists interspersed with massive marbles very resistant to weathering were identified after excavations on the grades of the left shoulder. In addition to being stratified and consistent with the foliation existing in the schists, marbles generate a high anisotropy and favor the development of karst cavities, a primary conditioner in dam projects (Xu and Yan, 2004).

\section{MATERIALS AND METHODS}

The high complexity and heterogeneity of geological materials present at the dam site motivated the adoption of the electrical resistivity method for the entire dam influence region, i.e., the dam site itself and its reservoir. This method is advantageous in karst environments, as it presents lower costs and shorter time of data acquisition and processing than those carried out exclusively by direct methods (Krishnaiah et al., 2012). This factor is essential considering its application in dam projects, as decisions need to be precise, dynamic, and expeditious.

The survey of geoelectric sections used the dipole-dipole method divided into two stages. In the first stage, electrodes were spaced every ten meters and ten levels (detailing up to thirty meters depth). In the second stage, a twenty-meter spacing was used between electrodes, alternating even and odd electrodes, with readings every ten meters (detailing up to $55 \mathrm{~m}$ depth). Figure 2 shows the layout of the twentyfive geoelectric sections that covered the entire area of interest, totaling $11,750 \mathrm{~m}$. The light green color represents young residual schist soils, while the yellow color represents fluvial-alluvial sediments.

\section{RESULTS AND DISCUSSION}

A chromatic scale was elaborated (Fig. 3) by correlating electrical resistivity signals with the geological information obtained by mapping and mixed drillings in order to facilitate the interpretation of readings obtained in ohm- $\mathrm{m}$. Limestone rocks are relatively dense and very resistant to electrical flow. Moreover, they become less dense and have good electrical conductivity in the presence of cavities filled by clayey materials. However, density tends to be zero if the cavity is filled by air due to the non-electrical conductivity in this medium, making the stretch highly resistive.

Figure 4 shows the data obtained from surveys on electrical resistivity is value maps at three different depths: the first depth is at the dam's foundation level (0m) (Fig. 4A), the second depth $20 \mathrm{~m}$ below $(-20 \mathrm{~m})$ (Fig. 4B), and the third depth $40 \mathrm{~m}$ below $(-40 \mathrm{~m})$ (Fig. 4C). The results and the electrical resistivity chromatic scale (Fig. 3) showed that electrical resistivity values decreased as depth increased, with a predominance of the light blue color. However, the rightmost part of the figures, upstream to the dam, shows an increase in electrical resistivity between 0 and $20 \mathrm{~m}$ deep, which is drastically reduced between 20 and $40 \mathrm{~m}$.

The low-depth resistivity zone can be interpreted as a geoelectric anomaly justified by four different hypotheses. The first hypothesis would be related to a stretch where the rocky massif is very fractured and/or failed, whit discontinuities open and saturated with water, resulting in low-resistivity zones. The second hypothesis would be related to a residual soil layer or very thick rock alteration located beneath floodplain sediments, which might have formed when the regional base level of the Samaná Peninsula was well-below the current level as the consequence of Quaternary glaciations. The third hypothesis would be related to a predominantly clay to sandy clay loam thick sediment pack deposited in the continental environment of an old closed basin, possibly associated with karst cavities, which could also have been developed when the regional base level of the Samaná Peninsula was well-below the current level. The fourth 
hypothesis would be related to the occurrence of differentiated strata interspersed with micaceous schists or igneous intrusions in them, which could be composed of minerals and/or rocks with high conductivities, such as sulfides, some metallic oxides, graphite, and native elements or similar.

Therefore, vertical and inclined direct drillings were carried out by the mixed method at sites identified with these hypotheses to confirm them or not.

Moreover, the highest electrical resistivity values were between 2000 and 2500 ohm-m throughout the geoelectric survey, being compatible with the presence of limestone rock or, more specifically, massive marble. No anomalies with very high resistivities were identified, which would be compatible with the occurrence of empty cavities and caves.

However, the observation of twenty-five geoelectric sections (Figs. 5 to 6) showed highresistivity zones in levels under $40 \mathrm{~m}$ deep in relation to the dam foundation level $(0 \mathrm{~m})$, often with a sequence of high-low-high resistivity strata.

Figure 5 shows three geoelectric sections on the axis and transversal to it. The results of geophysicists and mixed drillings showed that high-resistivity layers close to the dam foundation level are represented by marble bodies interspersed with schists. Residual soils essentially from schists and marble may occur below this layer, possibly due to differential weathering processes associated with geological structural compartments, which allow the development of residual soils at different mass depths. Low-resistivity stretches at high depths are represented by graphite schist rocks, denoting a low resistivity due to their mineralogical composition.

In sections such as L1 and L3 (Fig. 5), low-depth zones were identified in levels up to $55 \mathrm{~m}$ below the dam foundation. Resistivities observed in these zones are different from those in the dam axis section, indicating the presence of bedrock up to levels of $20 \mathrm{~m}$ or more.

Graphite schist portions may be present as residual soil (Fig. 6), showing behaviors such as those of other clayey residual soils, but with slightly higher resistivity.

Electrical resistivity signals are highly variable due to the mineralogical composition of schists at the dam site, but more conductive strata, composed of graphite schists, may be related to features that resemble water-filled cavities or saturated soil (Fig. 7A). Discontinuities occur preferentially in the same direction as rock foliation, which follows the regional dip of layers. Weathering processes develop along these discontinuities, forming residual soil layers between more resistive marble strata (Fig. 7B).

Discontinuities developed parallel to foliation can be filled by carbonate material (Fig. 8), and empty pores can often occur disseminated. These strata present stronger cores of high resistivity signals (schist interspersed with marbles) due to this characteristic (carbonate filling or empty pores).

Based on the above, geoelectric sections allowed the initial identification of punctual zones unfavorable to dam stability. Therefore, mixed drilling boreholes were executed more rationally, i.e., only at these sites. These drillings allowed confirming that low-resistance anomalies are associated with:

- alternations of distinct lithotypes (predominantly high-resistance graphite schist and limestones);

- geological structures (discontinuities developed along the foliation); and

- geomorphological structures (presence of karst zones).

These anomalies were identified as zones corresponding to low electrical resistivities. Intermediate resistivities are related to the existence of a thick layer of clay to sandy clay loam soil of low permeability, which would guarantee the watertightness of the reservoir to the project hydraulic load (approximately $10 \mathrm{~m}$ ). Moreover, high-resistivity passages were restricted to marble banks that occur interspersed with schists of various characteristics.

The association of indirect methods with traditional mixed drilling techniques avoided oversized initiatives for a better definition of the local geological and geotechnical conditions, which also allowed the optimization of the treatment of foundations and reservoir, reducing costs. Also, stress-strain analyses of the foundation massif were carried out under pre- and post-construction conditions of the dam (Leão et al., 2018). Geotechnical properties of the foundation massif needed to be improved by injecting cement grout because the dam has a concrete gravity design. Even with the foundation treatment stage not initially foreseen in the executive project, the correct interpretation of the information made it as adequate as possible, reducing costs. Also, the dam has been inaugurated in mid-2012 and has been in operation to date.

\section{CONCLUSIONS}

This study aimed to present a real case that demonstrates how to address geotechnical problems in weathered metamorphic terrains under tropical climate. The choice of the indirect method by (electrical resistivity), associated with later stages mapping and direct preliminary investigations, was enough to define points that represented zones of geotechnical problems associated with the mechanical behavior resulting from the weathering action on the rocks of the foundation.

The choice of indirect methods associated with direct methods was essential for an adequate geological-geotechnical characterization of projects located in zones of high geological complexity. In addition, the implementation of a complex and large construction such as a dam demands expeditious, adequate, and dynamic solutions. The adoption of both indirect and direct methods allows constructing 2D 
models, facilitating the understanding of geologicalgeotechnical conditioners of large projects. Secondarily, it is possible to develop more adequate characterization methods in substrates represented by alteration mantles, especially involving lithotypes recognized by a high complexity of their weathering profiles, such as schists and limestones.

The knowledge on the geotechnical properties of these materials, especially that of the weathered rock, allows the performance of less conservative complex constructions with a realistic budget, especially in massifs involving young residual soil and/or weathered rock developed under tropical climate. The correct method of investigation associated with the understanding of the behavior of weathered geological materials enables fast engineering solutions over the construction period, reducing costs and allowing adequate monitoring in the operational phase through the identification of possible problems in this stage.

\section{ACKNOWLEDGMENTS}

The authors acknowledge the financial support from CAPES.

\section{REFERENCES}

Behrestaghi, M.H.N., Seshagiri R.K. and Ramamurthy, T.: 1996, Engineering geological and geotechnical responses of schistose rocks from dam project areas in India. Engineering Geology, 44, $\mathrm{N}^{\circ} 1,183-201$. DOI: $10.1016 / \mathrm{S} 0013-7952(96) 00069-5$

Ertunç, A.: 1999, The geological problems of the large dams constructed on the Euphrates River (Turkey). Engineering Geology, 51, 167-182. DOI: $10.1016 / \mathrm{S} 0013-7952(97) 00072-0$

Goodman, R.E. and Ahlgren, C.S.: 2000, Evaluating safety of concrete gravity dam on weak rock: Scott Dam. Journal of Geotechnical and Geoenvironmental Engineering, 126, $\mathrm{N}^{\circ} 5,429-442$. DOI: 10.1061/(ASCE)1090-0241(2000)126:5(429)

Jakobsen, P.D. and Babendererde, T.: 2017, Preinvestigations for TBM tunneling. In: Proceedings of the world tunnel congress - Surface challenges Underground solutions. Bergen, Norway.

Kocbay, A. and Kiliç, R.: 2006, Engineering geological assessment of the Obruk dam site (Corum, Turkey). Engineering Geology, 87, N³-4, 141-148. DOI: $10.1016 /$ j.enggeo.2006.04.005

Krishnaiah, C., Panthulu, B.S., Shrotri, B.S. and Shrike, J.M.: 2012, Geophysical and hydrogeological investigations for studying seepage problems in dams. Journal of Hydraulic Engineering, 6, $\mathrm{N}^{\circ} 2,1-8$. DOI: $10.1080 / 09715010.2000 .10514672$
Leão, M.F., Pacheco, M.P. and Danziger, B.R.: 2018. Stressstrain analysis of a concrete dam in predominantly anisotropic residual soil. Soils and Rocks, 41, N², 171-181. DOI: 10.28927/SR.412171

Leão, M.F., Barroso, E.V., Polivanov, H., Marques, E.A.G and Vargas Jr., E.A.: 2017, Weathering of metapelites from Quadrilátero Ferrífero mineral province, southeastern Brazil. Bulletin of Engineering Geology and the Environment, 78, $\mathrm{N}^{\circ} 1,19-33$.

DOI: $10.1007 / \mathrm{s} 10064-017-1036-1$

Leão, M.F.: 2015, Analysis strain stress of a concrete dam in residual soil predominantly anisotropic. PH.D. Dissertation, State University of Rio de Janeiro, Department of Civil Engineering, Rio de Janeiro, RJ, Brazil, (in Portuguese).

Leão, M.F.: 2011, Geological-geomechanical modeling of San Juan Dam, Dominican Republic. PH.D. Dissertation, Federal University of Rio de Janeiro, Department of Geology, Rio de Janeiro, RJ, Brazil, (in Portuguese).

Macfarlane, D.F.: 2009, Observations and predictions of the behavior of large, slow-moving landslides in schist, Clyde Dam reservoir, New Zealand. Engineering Geology, 109, $\mathrm{N}^{\circ} 1,5-15$. DOI: 10.1016/j.enggeo.2009.02.005

Mollat, H., Wagner, B.M., Cepek, P. and Weiss, W.: 2004, Geological Map of the Dominican Republic 1:250.000. Schweizerbart Science Publishers. Germany, 100 pp., (in Spanish).

Ramana, Y.V. and Gogte, B.S.: 1982, Quantitative studies of weathering in saprolitized charnockites associated with a landslip zone at the Porthmund dam, India. Engineering Geology, 19, $\mathrm{N}^{\circ} 1,29-46$.

Rogers, G.D., Kahler, C. and Deaton, S.: 2006, Foundation investigation at Hickory Log Creek Dam, Canton. Proc. GeoCongress 2006, Georgia, ASCE, 1-6. DOI: $10.1061 / 40803(187) 146$

$\mathrm{Xu}, \mathrm{R}$. and Yan, F.: 2004, Karst geology and engineering treatment in the Geheyan Project on the Qingjiang River, China. Engineering Geology, 76, 155-164. DOI: $10.1016 /$ j.enggeo.2004.06.012

Wang, Y.S. and Liu, S.: 2005, Treatment for a fully weathered rock dam foundation. Engineering Geology, $77, \mathrm{~N}^{\circ} 1,115-126$.

DOI: 10.1016/j.enggeo.2004.08.006

Wiesner, E. and Ewert, F.: 2013, Resolving serious seepage through karstified limestone at the Mujib Dam, Jordan. Bulletin of Engineering Geology and Environment, 72, 149-162.

DOI: $10.1007 / \mathrm{s} 10064-012-0452-5$ 


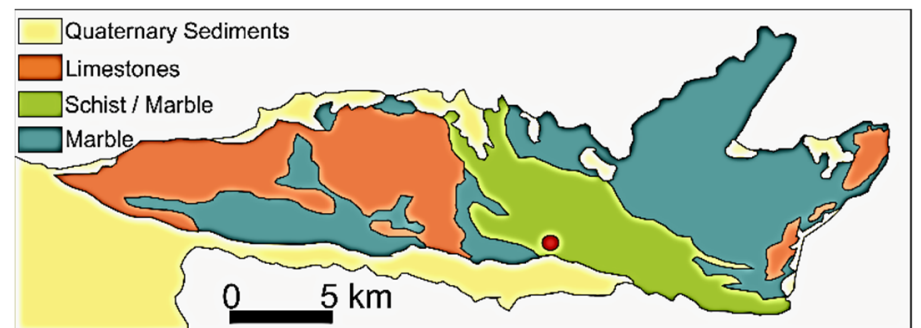

Fig.1 Geological map of the Samaná Peninsula, with the study area in red.

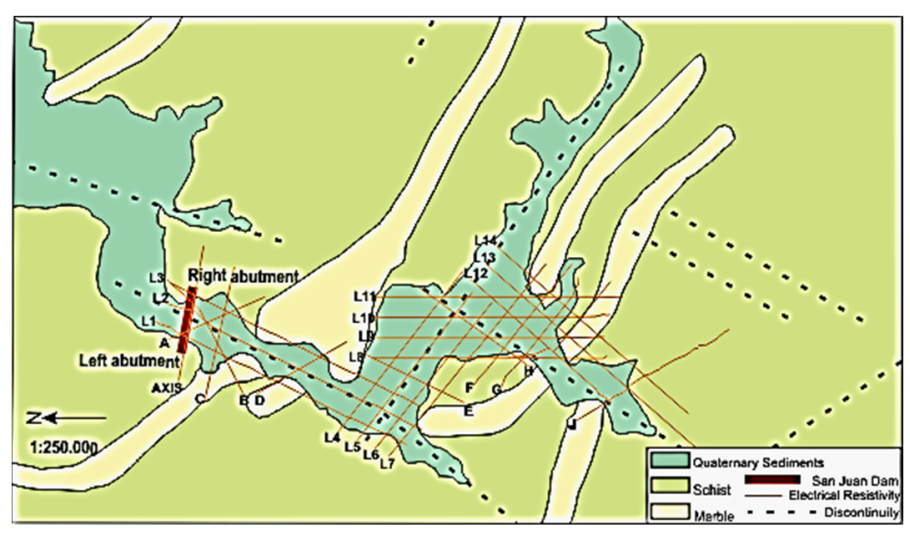

Fig. 2 Geoelectric sections arranged over the dam influence area (orange lines).

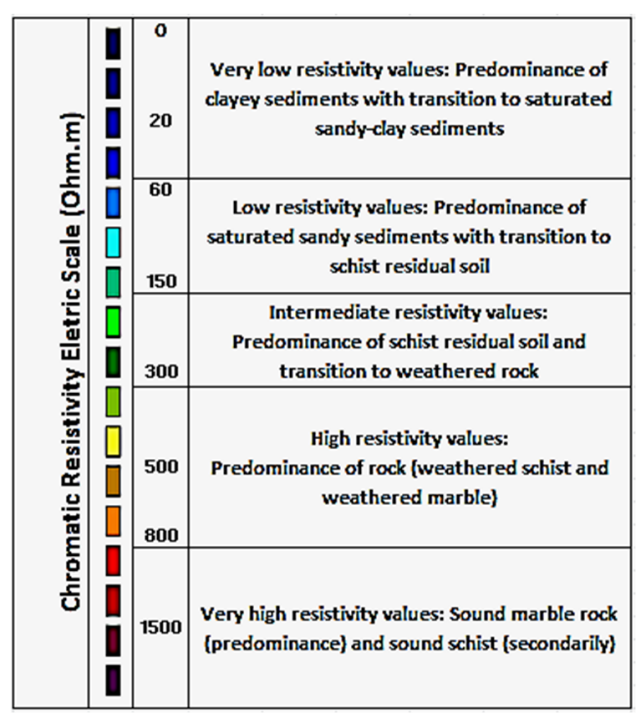

Fig.3 Correlation between electrical resistivity values and geological materials in the study area.
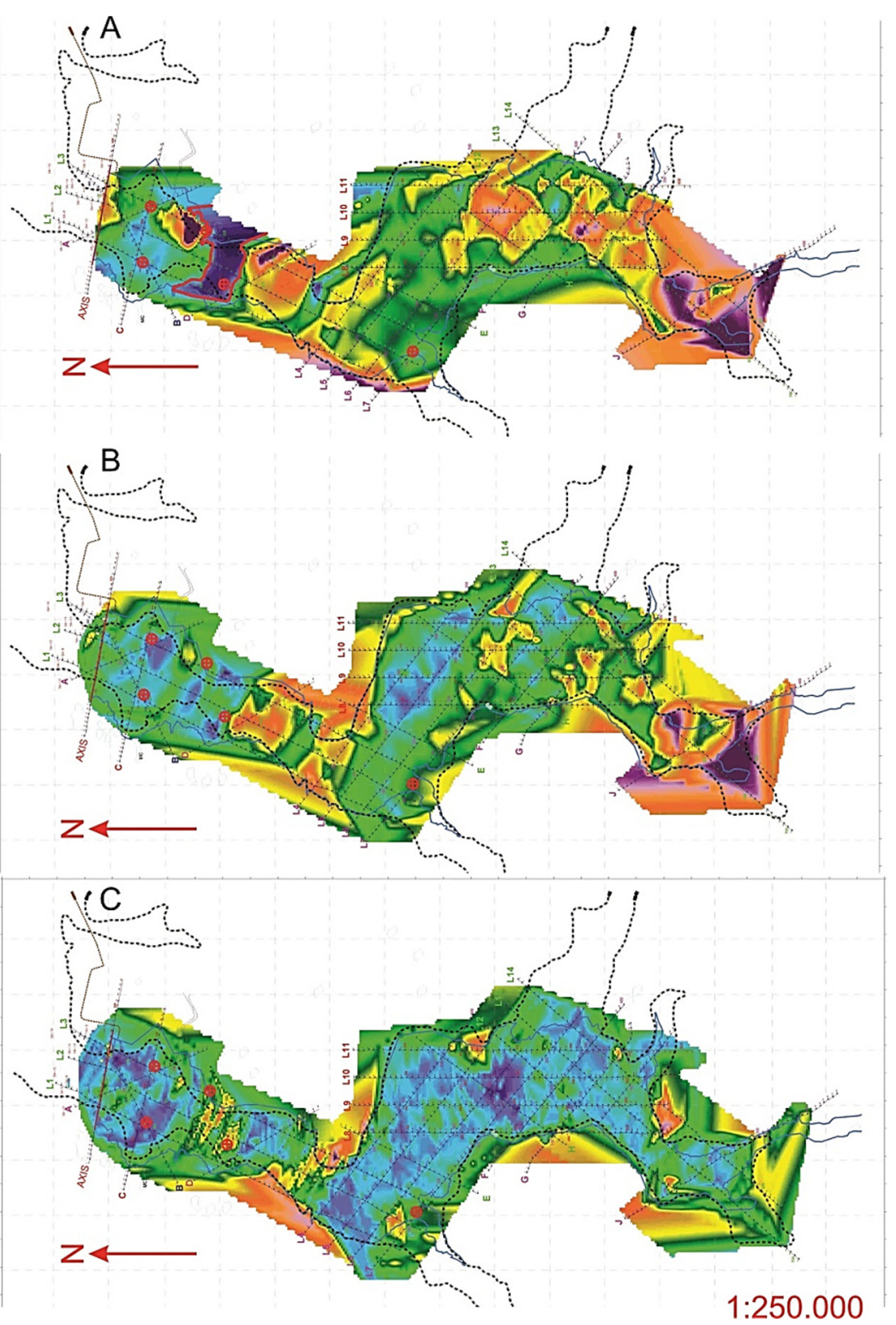

Fig. 4 Electrical resistivity isovalue maps for dam foundation levels of $0 \mathrm{~m}$ (A), $20 \mathrm{~m}$ below (B), and $40 \mathrm{~m}$ below (C). Red circles indicate mixed drilling points after the geoelectric survey. 

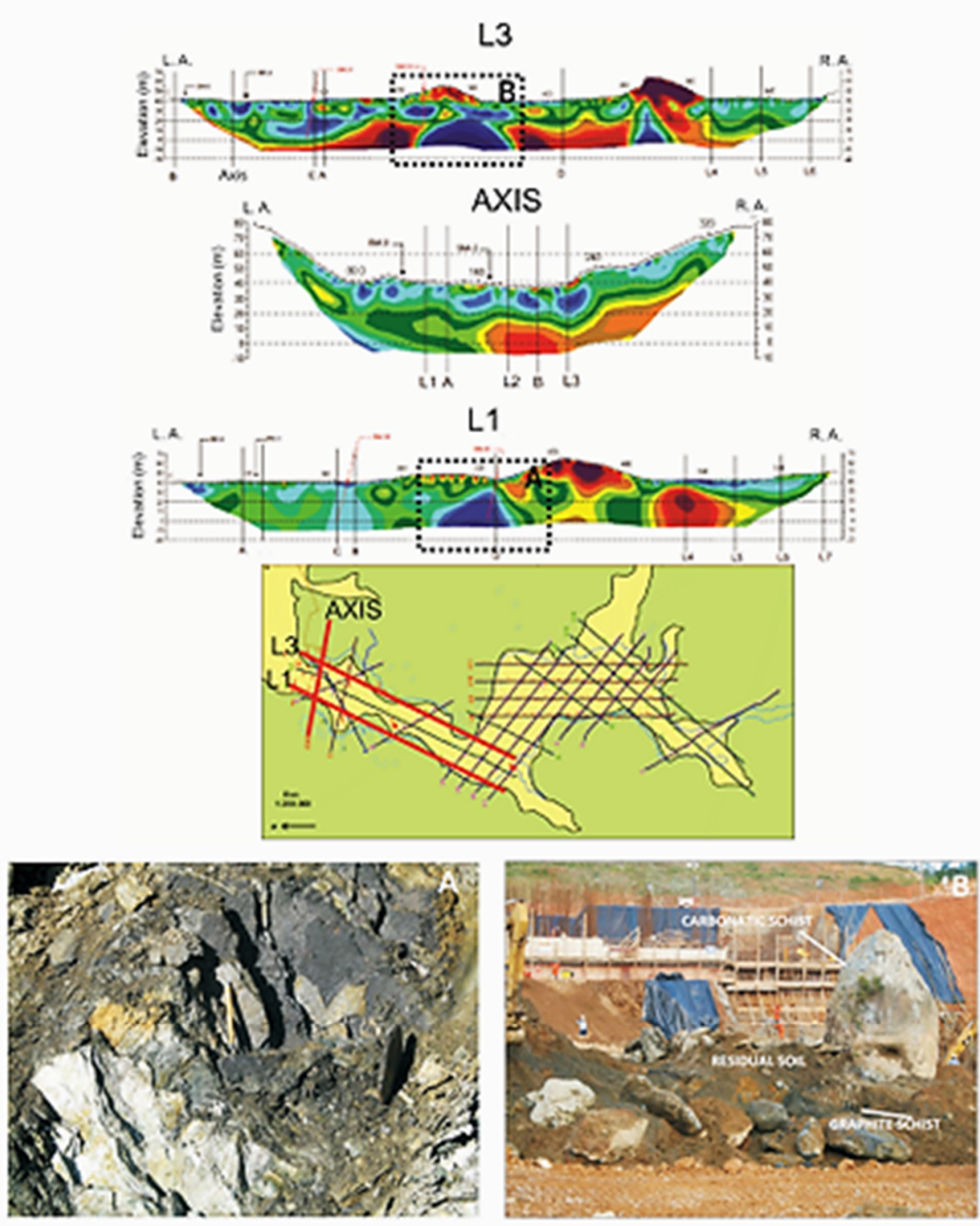

Fig. 5 Geoelectric sections along the dam axis and parallel to it with the main geological characteristics (A and B highlighted in the sections by dashed squares).
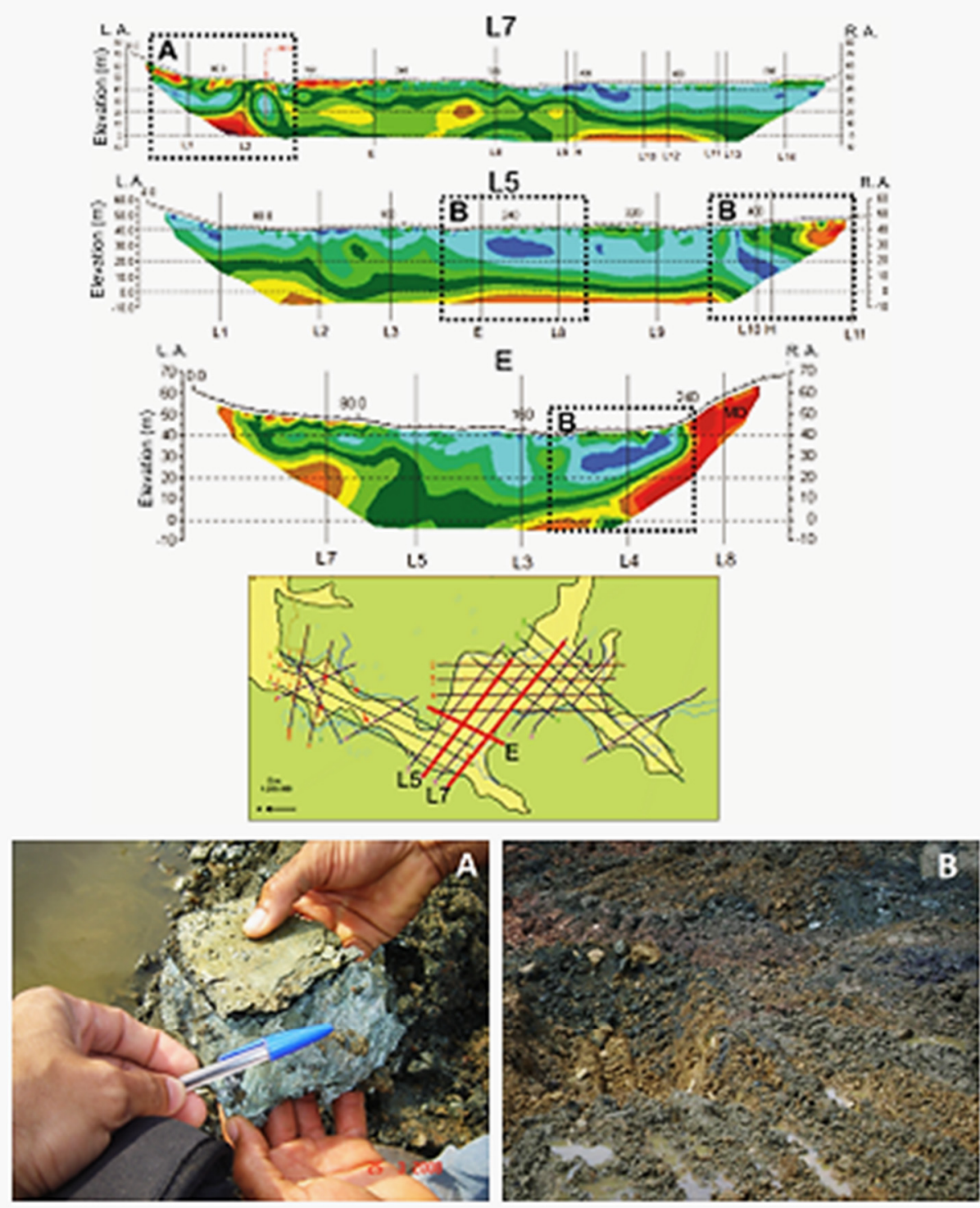

Fig. 6 Geoelectric sections in the middle portion of the most western dam reservoir with the main geological characteristics (A and B highlighted in the sections by dashed squares). 

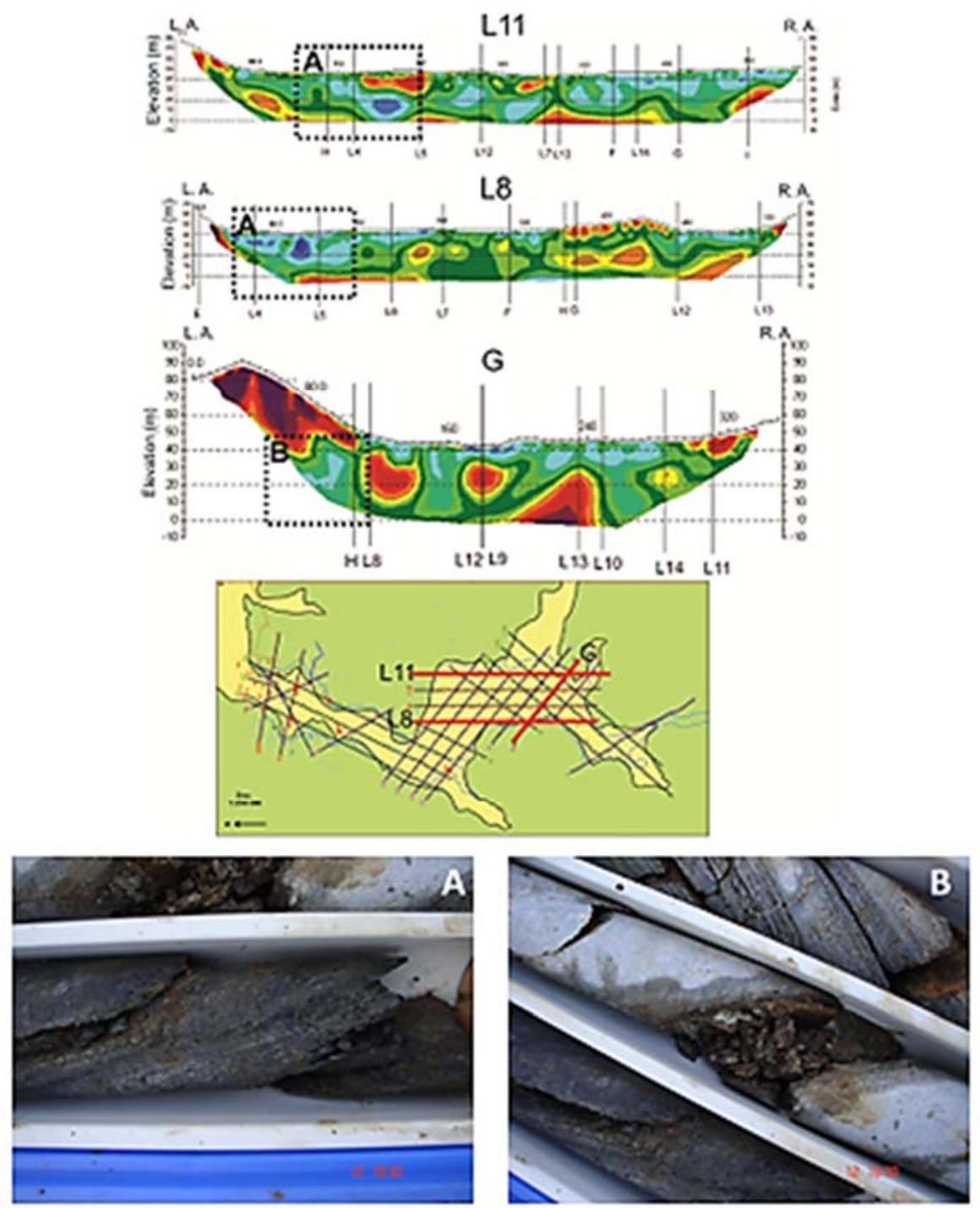

Fig. 7 Geoelectric sections in the middle portion of the most eastern dam reservoir with the main geological characteristics obtained from drilling cores (A and B highlighted in the sections by dashed squares).
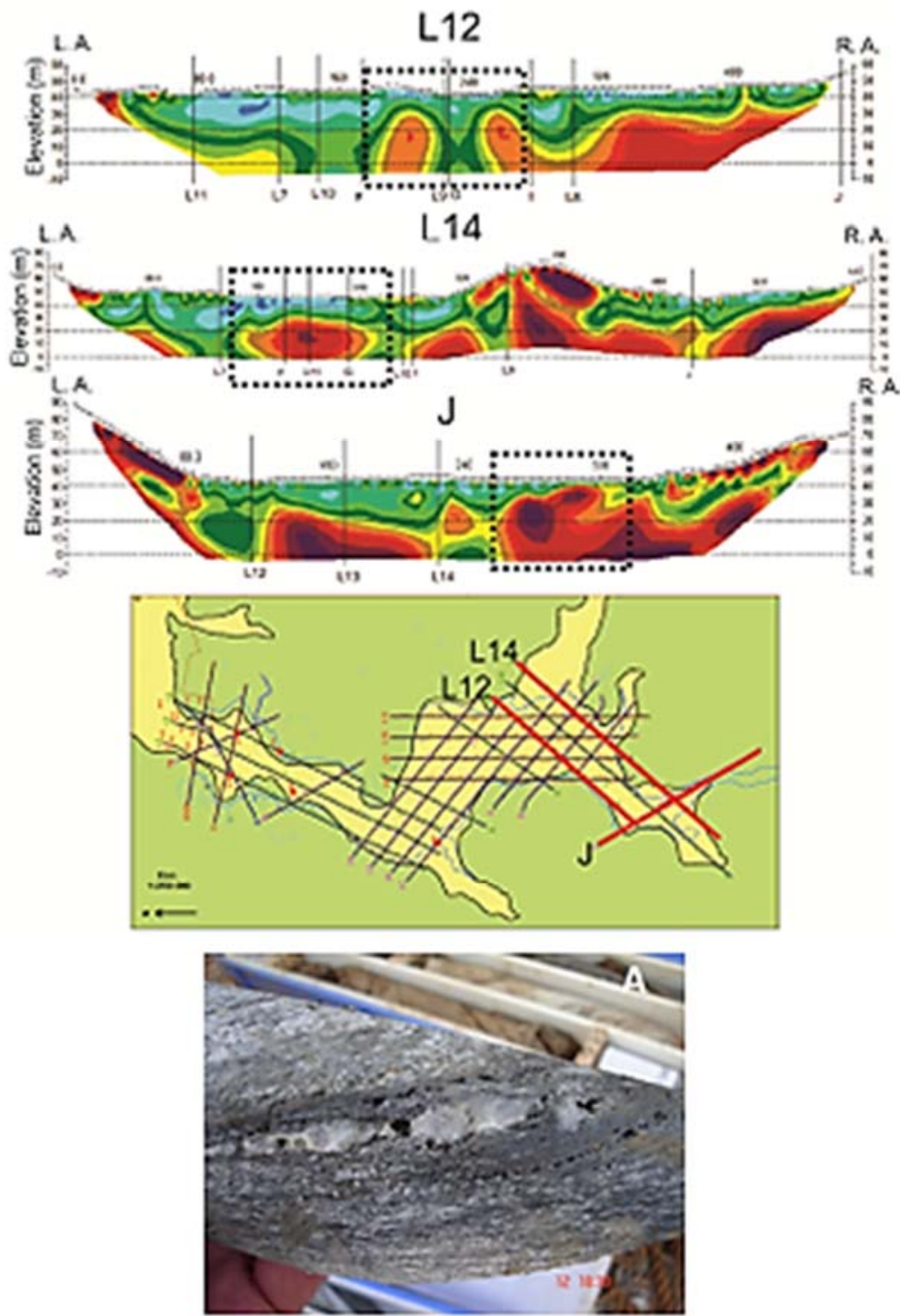

Fig. 8 Geoelectric sections in the final portion of the dam reservoir with carbonate filling in the drilling core (dashed square in the sections). 